\title{
Addendum
}

\section{A Short and Efficient Route from myo- to neo-Inositol}

Pablo Wessig,* Kristian Möllnitz, Sebastian Hübner Synlett 2010, 1497.

In this article, page 1497, right column, third paragraph, it reads: "Besides the difficulties to scale up this first step (a run in a $2800 \mathrm{ml}$ flask gave only $160 \mathrm{mg}$ product)..." The authors would like to qualifiy this statement and point out that an improved synthesis was presented: Endoma, M. A.; Bui, V. P.; Hansen, J.; Hudlicky, T. Org. Process Res. Dev. 2002, 6,525 . The authors apologize for the lack of citation. 